\title{
FDA eManufacturing Terminology
}

National Cancer Institute

\section{Source}

National Cancer Institute. FDA eManufacturing Terminology. NCI Thesaurus. Code

C112906.

Terminology developed to support manufacturing efforts of the FDA. 